\title{
Thermal and Dielectric Behavior Studies of Poly(Arylene Ether Sulfone)s with Sulfonated and Phosphonated Pendants
}

\author{
Shimoga D. Ganesh, ${ }^{1,2}$ Vasantakumar K. Pai, ${ }^{1}$ \\ Mahadevappa Y. Kariduraganavar, ${ }^{3}$ and Madhu B. Jayanna ${ }^{4}$ \\ ${ }^{1}$ Department of Industrial Chemistry, School of Chemical Sciences, Jnana Sahyadri, Kuvempu University, Shankaraghatta, \\ Shimoga, Karnataka 577 451, India \\ ${ }^{2}$ Centrum Polymerních Systémů, Univerzita Tomáše Bati ve Zlíně, Univerzitní Institut, Trúida Tomáše Bati 5678 , 76001 Zlín, \\ Czech Republic \\ ${ }^{3}$ Department of Chemistry and Center of Excellence in Polymer Science, Karnatak University, Dharwad 580 003, India \\ ${ }^{4}$ Department of Physics, Government Science College, Chitradurga, Karnataka 577501, India
}

Correspondence should be addressed to Shimoga D. Ganesh; icganeshin@gmail.com

Received 28 April 2016; Revised 4 July 2016; Accepted 26 July 2016

Academic Editor: Matjaz Valant

Copyright (C) 2016 Shimoga D. Ganesh et al. This is an open access article distributed under the Creative Commons Attribution License, which permits unrestricted use, distribution, and reproduction in any medium, provided the original work is properly cited.

The present paper discusses the aspects of the synthesizing valeric acid based poly(ether sulfone)s with active carboxylic acid pendants (VALPSU) from solution polymerization technique via nucleophilic displacement polycondensation reaction among $4,4^{\prime}$ dichlorodiphenyl sulfone (DCDPS) and 4,4'-bis(4-hydroxyphenyl) valeric acid (BHPA). The conditions necessary to synthesize and purify the polymer were investigated in some detail. The synthesized poly(ether sulfone)s comprise sulfone and ether linkages in addition to reactive carboxylic acid functionality; these active carboxylic acid functional groups were exploited to hold the phenyl sulphonic acid and phenyl phosphonic acid pendants. The phenyl sulphonic acid pendants in VALPSU were easily constructed by altering active carboxylic acid moieties by sulfanilic acid using $\mathrm{N}, \mathrm{N}^{\prime}$-dicyclohexylcarbodiimide (DCC) mediated mild synthetic route, whereas the latter one was built in two steps. Initially, polyphosphoric acid condensation with VALPSU by 4-bromoaniline and next straightforward palladium catalyzed synthetic route, in both of which acidic pendants are clenched by polymer backbone via amide linkage. Without impairing the primary polymeric backbone modified polymers were prepared by varying the stoichiometric ratios of respective combinations. All the polymers were physicochemically characterized and pressed into tablets; electrical contacts were established to study the dielectric properties. Finally, the influence of the acidic pendants on the dielectric properties was examined.

\section{Introduction}

Ionomers aim to control the dielectric properties in supramolecular assemblies [1-6]. Many attempts were noticed recently to synthesize ions containing polymers hanging to the macromolecular systems via amide linkages $[7,8]$, with expected dielectric properties owing to the flexibility of molecular chemistry and the subtleties of supramolecular interactions [9-11]. Several challenges were overcome recently, such as aromatic poly(ether ketone)s with pendant sulfonic acid phenyl groups [12], synthesis of highly sulfonated poly(arylene ether sulfone) random (statistical) copolymers via direct polymerization [13], comb-shaped poly(arylene ether sulfone)s [14], and phosphonic acid containing poly(arylene ether)s [15]; mild and effective protocols to modify the polymer chains at room temperature opened new prospects as well [16]. The covalent linkages of these different classes of molecules to a single linear polymer chain can produce reactive and functional polymeric systems [17-19] with different physical properties and functions.

Aromatic poly(ether sulfone)s have been paid much attention as high performance polymers and they have been widely used $[20,21]$ by developing new types of bisphenol monomers [22], with sulfonic and phosphonic acid pendants 
for technological importance [23]. Incorporation of pendant ionic block units [24] to this poly(arylene ether sulfone)s in a macromolecular architecture is an attractive way of creating new supramolecular structures due to its ability to segregate incompatible segment of individual molecules $[25,26]$. The resulting ionomers based on related ionic segments may also serve as models providing insight into the ordering of complicated technological systems [27, 28]. Systematic backbone and sequence modification constitutes a powerful approach to learn about the fundamental interactions of ionomers that contribute to the stability of modified polymer structure [29].

The present work is devoted to the modification of VALPSU polymer; the derived name represents valeric acid based poly(arylene ether sulfone)s. Herein we report profound structural variations of VALPSU based on the sulfonic and phosphonic acid segments via amide linkages. More recently, we have established the effect of varying the stoichiometric molar ratio of HEPES on the dielectric properties of VALPSU [30]. We are investigating the influence of different molar ratios of the ionic pendants, in addition to introducing other types of phosphonic and sulfonic acid moieties. Mapping out the structural diversity of these ionic organic structural units is of interest in the building of macromolecules, with potential applications in technical field [31].

\section{Experimental}

2.1. Materials. Dicyclohexylcarbodiimide (DCC) and $N, N^{\prime}$ dimethylformamide (DMF) were purchased from Sigma Aldrich. 4-Bromoaniline and sulfanilic acid were purchased from HIMEDIA Chemicals. Polyphosphoric acid (PPA) was procured from Spectrochem Pvt. Ltd. All the other chemicals were of reagent grade and used without further purification. Double distilled water was used throughout the study. DMF was dried over $5 \AA$ molecular sieves for at least $48 \mathrm{~h}$ before use. However, VALPSU polymer was not available commercially; the detailed synthetic protocol was described in our previously reported literature [30].

2.2. Instrumentation. Thermogravimetric analysis (TGA) was performed on a PerkinElmer Diamond TGA/DTA thermogravimetric analyzer at a heating rate of $10^{\circ} \mathrm{C} / \mathrm{min}$ in a nitrogen atmosphere. The ${ }^{1} \mathrm{H} \&{ }^{13} \mathrm{C}$ NMR spectra were recorded on a BrukerAvance $400 \mathrm{MHz}$ spectrometer using tetramethylsilane (TMS) as an internal standard. The dielectric measurements were carried out using impedance analyzer model HIOKI 3352-50 HiTESTER Version 2.3. Samples of powdered polymer were pressed into tablets and sandwiched between two silver-plated stainless steel electrodes. Silver paint (ELTECKS preparation number 1228-C) was coated on both flat surfaces of the pressed tablet and the electrical contacts to the samples were made using the same silver paint to the electrodes. The electrical contacts were checked to verify the ohmic connection. The measurements were carried out at room temperature in the frequency range $50 \mathrm{~Hz}-5 \mathrm{MHz}$. The capacitance value $(C)$ and ac conductance $(G)$ were directly obtained from the instrument. The dielectric constant $\left(\varepsilon^{\prime}\right)$ and ac conductivity $\left(\sigma_{\mathrm{ac}}\right)$ values are calculated using the relations $\varepsilon^{\prime}=C_{p} d / \varepsilon_{o} A$ and $\sigma_{\mathrm{ac}}=G d / A$, respectively, where " $d$ " is the thickness of the polymer tablet, " $A$ " is the cross-sectional area, and $\varepsilon_{o}$ is the permittivity of the free space. All these measurements were made under dynamic vacuum.

\subsection{Method}

2.3.1. Synthesis of VALPSU-SUL-60 Polymer (PS-60). Onestep direct modification of VALPSU poly(ether sulfone)s with 60 weight \% of sulfanilic acid (PS-60) is discussed. To a $100 \mathrm{~mL}$ three-neck flask equipped with a mechanical stirrer and a nitrogen inlet/outlet, $1.0 \mathrm{~g}$ of VALPSU and $0.623 \mathrm{~g}$ $(3.0 \mathrm{mmol})$ of DCC [the molar calculations are based on the monomer content "4,4-bis(4 hydroxyphenyl)pentanoic acid" for the synthesis of VALPSU polymer] were added and stirred by adding $10 \mathrm{~mL}$ dry DMF to form the soluble and more reactive derivative. The solution was stirred at room temperature for $30 \mathrm{~min}$ until complete dissolution of the polymer and DCC and then $0.6 \mathrm{~g}$ of sulfanilic acid was added along with additional $5 \mathrm{~mL}$ of DMF using syringe into the reaction mixture. The thick viscous reaction mixture was stirred at ambient temperature for $22 \mathrm{~h}$; the sulfanilic acid modified polymer was precipitated into an excess of $5 \%$ methanolic solution. The precipitated polymer was collected by filtration and pulverized, washed several times with $1: 1$ acetone and water mixture, and finally washed repeatedly with hexane. The resulting white polymer PS-60 was dried under vacuum at $60^{\circ} \mathrm{C}$ for $24 \mathrm{~h}$.

Yield: 85\%; FT-IR (diamond window, $\left.\mathrm{cm}^{-1}\right) 1732(\mathrm{C}=\mathrm{O}$, sym.), 1643 ( $\mathrm{C}=\mathrm{O}$, asym.), 1086 ( $\mathrm{S}=\mathrm{O}$, asym.), 1009 ( $\mathrm{S}=\mathrm{O}$, sym.), 1241 ( $\mathrm{S}=\mathrm{O}$, sulfone). ${ }^{1} \mathrm{H}$ NMR (400 MHz, DMSO- $d_{6}$ ): $\delta=0.98-1.27,1.46-1.87,1.97-2.6,7.03$ (br s, 1H), 7.07-7.08 (br s, $1 \mathrm{H}$ ), 7.20-7.23 (br s, 1H), 7.27-7.28 (br s, $1 \mathrm{H}$ ), 7.61 (br s, $1 \mathrm{H}$ ), 7.63 (br s, $1 \mathrm{H}), 8.07-8.09(d, 2 \mathrm{H})$.

A similar procedure was followed for the synthesis of polymers VALPSU-SUL-20 (PS-20) and VALPSU-SUL-40 (PS-40). The spectral and analytical data are given below.

2.3.2. VALPSU-SUL-40 Polymer (PS-40). Yield: 85\%; FT-IR (diamond window, $\left.\mathrm{cm}^{-1}\right) 1734(\mathrm{C}=\mathrm{O}, \operatorname{sym}),. 1646(\mathrm{C}=\mathrm{O}$, asym.), 1084 ( $\mathrm{S}=\mathrm{O}$, asym.), 1012 ( $\mathrm{S}=\mathrm{O}$, sym.), $1243(\mathrm{~S}=\mathrm{O}$, sulfone). ${ }^{1} \mathrm{H}$ NMR $\left(400 \mathrm{MHz}, \mathrm{DMSO}-d_{6}\right): \delta=0.99-1.27,1.47-$ $1.88,1.96-2.48,7.03$ (br s, 1H), 7.07-7.08 (br s, 1H), 7.20-7.22 (br s, 1H), 7.26-7.28 (br s, $1 \mathrm{H}), 7.60$ (br s, $1 \mathrm{H}), 7.62$ (br s, $1 \mathrm{H}$ ), 8.07-8.09 $(d, 2 \mathrm{H})$.

2.3.3. VALPSU-SUL-20 Polymer (PS-20). Yield: 80\%; FT-IR (diamond window, $\left.\mathrm{cm}^{-1}\right) 1733(\mathrm{C}=\mathrm{O}$, sym.), $1645(\mathrm{C}=\mathrm{O}$, asym.), 1081 ( $\mathrm{S}=\mathrm{O}$, asym.), 1014 ( $\mathrm{S}=\mathrm{O}$, sym.), 1245 ( $\mathrm{S}=\mathrm{O}$, sulfone). ${ }^{1} \mathrm{H}$ NMR $\left(400 \mathrm{MHz}, \mathrm{DMSO}-d_{6}\right): \delta=0.99-1.27,1.47-$ $1.88,1.96-2.48,7.03$ (br s, 1H), 7.07-7.08 (br s, 1H), 7.20-7.22 (br s, 1H), 7.26-7.28 (br s, 1H), 7.60 (br s, 1H), 7.62 (br s, 1H), 8.07-8.09 $(d, 2 \mathrm{H})$.

The chemical reaction routes for sulfonic acid and phosphonic acid modified VALPSU are presented in Figures 1 and 2 , respectively. 


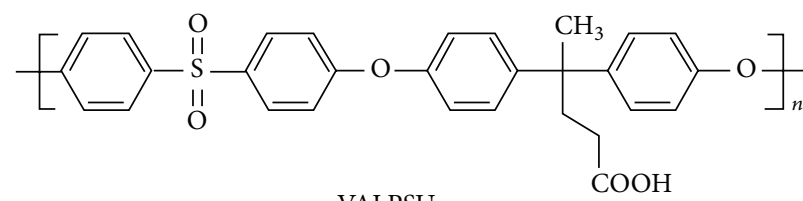

VALPSU

$\mathrm{COOH}$

$$
\begin{aligned}
& \text { DCC, RT } \\
& \text { Sulfanilic acid }
\end{aligned}
$$

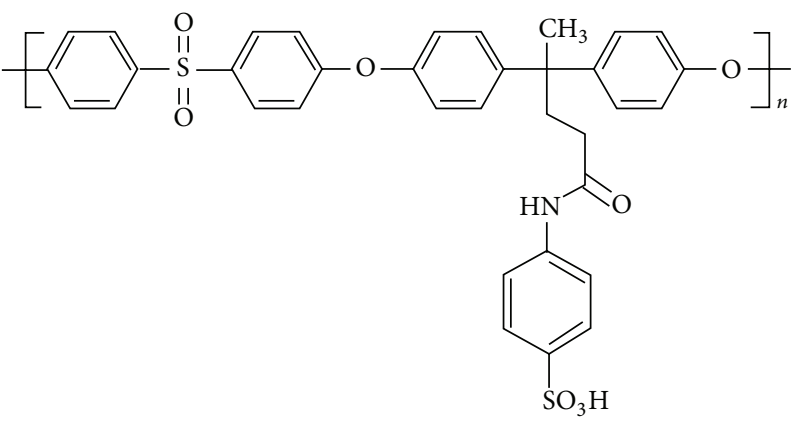

FIGURE 1: Synthesis of sulfanilic acid modified VALPSU polymer.

2.3.4. Synthesis of VALPSU-PHOS-20 Polymer (PP-20). Typical procedure to modify VALPSU polymer with 20 weight $\%$ of 4-bromoaniline is discussed. Pulverized mixture of VALPSU ( $1 \mathrm{~g})$ and 4-bromoaniline $(0.2 \mathrm{~g})$ was taken in a $100 \mathrm{~mL}$ round bottom flask fitted with a mechanical stirrer and a nitrogen inlet/outlet, $10 \mathrm{~g}$ of polyphosphoric acid was added, and the reaction mixture was stirred initially at $120^{\circ} \mathrm{C}$ for $2 \mathrm{~h}$. The heating was continued to $150^{\circ} \mathrm{C}$ for another $20 \mathrm{~h}$. The reaction mixture was cooled to $80^{\circ} \mathrm{C}$ and poured to $5 \%$ cold hydrochloric acid solution to precipitate the light brown coloured polymer. The polymer (PP-20) so obtained was repeatedly washed with the hot water and dried under vacuum at $60^{\circ} \mathrm{C}$ for $24 \mathrm{~h}$.

2.3.5. Synthesis of VALPSU-PHOS-ESTER-20 Polymer (PE20). PP-20 (0.6 g, $2 \mathrm{mmol})$ polymer was dissolved in dry DMSO under nitrogen atmosphere; to this $2.8 \mathrm{~mL}$ of triethyl amine is added followed by the addition of $2.6 \mathrm{~mL}$ of diethyl phosphite. The solution was stirred for $20 \mathrm{~min}$ at $60^{\circ} \mathrm{C}$. $0.6 \mathrm{mmol}$ of the catalyst tetrakis(triphenylphosphine)palladium was added in one lot and temperature is raised to $100 \circ \mathrm{C}$. The precipitated polymer was redissolved by adding additional $5 \mathrm{~mL}$ of DMSO after $2 \mathrm{~h}$ and allowed to stir for $10 \mathrm{~h}$ at the same temperature. The reaction mixture was cooled to room temperature and poured into $75 \mathrm{~mL}$ of methanol containing $10 \mathrm{vol} \%$ concentrated hydrochloric acid (37\%) to obtain a creeping product after $30 \mathrm{~min}$. The polymer that contained the catalyst was washed in hot methanol and hot water for several times. After drying in a vacuum oven, the polymer powder was dissolved in DMSO and reprecipitated in methanol that contained $10 \mathrm{vol} \%$ concentrated hydrochloric acid (37\%). The polymer was thoroughly washed with hot water and methanol repeatedly to obtain the light grey phosphonated ester polymer (PE-20).

2.3.6. Hydrolysis of VALPSU-PHOS-ESTER-20 Polymer (PE-20). VALPSU-PHOS-ACID-20 polymer (PA-20) was obtained by the acid hydrolysis of PE-20 by hydrobromic acid ( $\mathrm{HBr}$ ) solution $(48 \%)$. $0.5 \mathrm{~g}$ of suspended PE-20 polymer in $5 \mathrm{~mL}$ of $\mathrm{HBr}(48 \%)$ was refluxed for about $70 \mathrm{~h}$. The hydrolysed polymer was washed thoroughly with hot water $\left(80^{\circ} \mathrm{C}\right)$ over $30 \mathrm{~h}$ to remove excess acid, till the $\mathrm{pH}$ of the filtrate water becomes neutral and then off-white fluffy polymer (PA-20) was dried at $60^{\circ} \mathrm{C}$ for $12 \mathrm{~h}$.

\section{Results and Discussion}

3.1. Synthesis and Characterization. The sulfanilic acid modification reaction to the VALPSU polymer was achieved through simple and efficient room temperature DCC catalyzed condensation route. The chemical structures of all the sulfanilic acid modified VALPSU polymers were characterized and confirmed with FTIR and NMR spectroscopic techniques.

Pendant phenyl sulfonic acid units are constructed via simple DCC coupling conditions at ambient temperature by simple one-step process to afford amide linked ionic pendants to VALPSU. Whereas phosphonic acid pendants to VALPSU are built in three-step synthetic procedure, initially VALPSU was made to react with 4-bromoaniline by polyphosphoric acid condensation protocol to get 4-bromophenyl units as a part of VALPSU. In the latter process, these 4-bromophenyl pendants are transformed successfully to phosphonic ester derivatives, which are later converted to phosphonic acid 

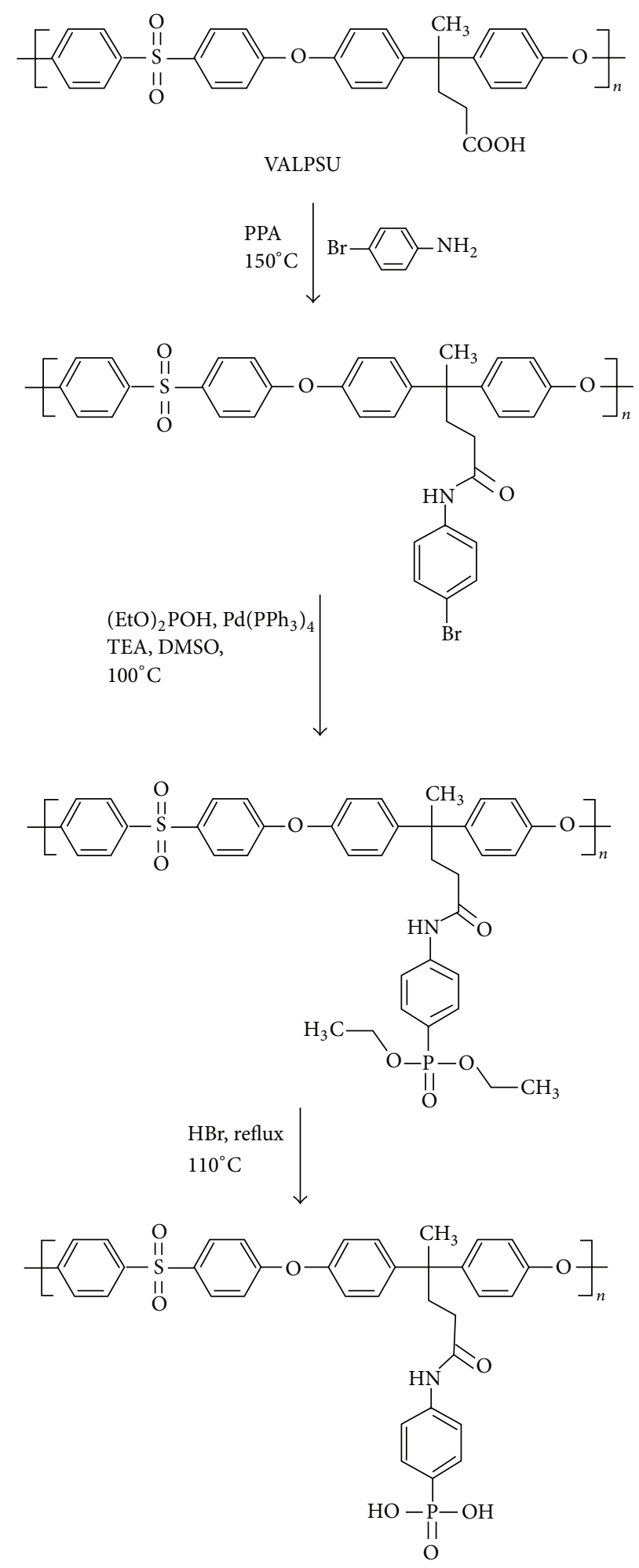

FIGURE 2: Synthesis of phosphonic acid modified VALPSU polymer. 
TABLE 1: Kinetic and thermodynamic parameters of modified sulfonated VALPSU.

\begin{tabular}{lcccccc}
\hline Samples & Decomposition range $\left({ }^{\circ} \mathrm{C}\right)$ & $E_{a}(\mathrm{~kJ} / \mathrm{mol}) \times 10^{-3}$ & $\ln A$ & $\Delta H(\mathrm{~kJ} / \mathrm{mol})$ & $\Delta S(\mathrm{~kJ} / \mathrm{K})$ & $\Delta G(\mathrm{~kJ} / \mathrm{mol})$ \\
\hline \multirow{2}{*}{ PS-20 } & $140-350$ & 0.217 & -12.06 & -4.321 & -164.11 & 85.31 \\
& $510-645$ & 1.659 & -9.853 & -7.058 & -160.91 & 136.64 \\
\hline \multirow{2}{*}{ PS-40 } & $160-370$ & 0.355 & -11.562 & -4.459 & -163.91 & 87.92 \\
& $160-370$ & 0.883 & -10.567 & -7.068 & -160.00 & 136.89 \\
\hline \multirow{2}{*}{ PS-60 } & $170-315$ & 1.031 & -10.443 & -4.276 & -163.88 & 90.56 \\
& $530-640$ & 2.467 & -9.366 & -7.124 & -159.96 & 137.12 \\
\hline
\end{tabular}

moiety by simple acid hydrolysis. Palladium catalyzed synthetic route was adopted to convert 4-bromophenyl moieties to respective phosphonic ester derivatives; the polymers which are completely soluble in DMSO were effectively converted. But the PP-60 polymer was insoluble in DMSO. So, respective PE-60 and PA-60 were not obtained.

The ${ }^{1} \mathrm{H}$ and ${ }^{13} \mathrm{C}$ NMR spectrums of VALPSU-SUL-40 polymer (PS-40) were shown in Figure S1 and Figure S2 in Supplementary Material available online at http://dx.doi .org/10.1155/2016/7271959. The characteristic chemical shifts of ethylene groups appeared at around 1.22 to $2.49 \mathrm{ppm}$ and aromatic peaks at around 7.03 to $8.09 \mathrm{ppm}$. In ${ }^{13} \mathrm{C}$ NMR spectra of PS-40 (Figure S2), characteristic chemical shifts of aliphatic and aromatic carbon signals appeared in respective regions as expected. A lower chemical shift in the carbon signals is observed for PS-40 polymer as compared to VALPSU; this diamagnetic shift is induced from very weak base, amide bonds; this relative lack of basicity is explained by the electron-withdrawing nature of the carbonyl group where the lone pair of electrons on the nitrogen is delocalized by resonance. The ${ }^{1} \mathrm{H}$ NMR spectra of PP-40 polymer (Figure S3) showed a signal which clearly indicates the conversion of part of carboxylic acid units into hanging 4-bromophenyl pendants to VALPSU via amide linkage. From the NMR spectrum of PA-40 (Figure S4), it is clear that phosphonic ester in PE-40 is hydrolysed to respective phosphonic acid.

3.2. Thermal Analysis. From the TGA plot shown in Figure 3, it is observed that initial weight loss in case of phenyl sulfonic acid modified polymers was attributed to the desulfonation of sulfonic groups, where $-\mathrm{SO}_{3} \mathrm{H}$ was easily exterminated by releasing $\mathrm{H}_{2} \mathrm{O}, \mathrm{SO}_{2}$, and other sulfur oxides, which is not observed in starting VALPSU and which is observed for modified polymers below $200^{\circ} \mathrm{C}$. Another major weight loss is witnessed for the decomposition of pendant sulfonic units attached via amide linkages and remaining carboxylic acid groups from main VALPSU polymer backbone at around $250-350^{\circ} \mathrm{C}$

Second major degradation step is observed in the range of $510-650^{\circ} \mathrm{C}$ and it accounted for the decomposition of main polymeric chain. No weight loss is observed before $110^{\circ} \mathrm{C}$ because the polymers were totally dried before analysis. Kinetic and thermodynamic parameters were calculated using Broido's method [32]. Broido has developed a model and the activation energy associated with each stage of decomposition was also evaluated by this method.

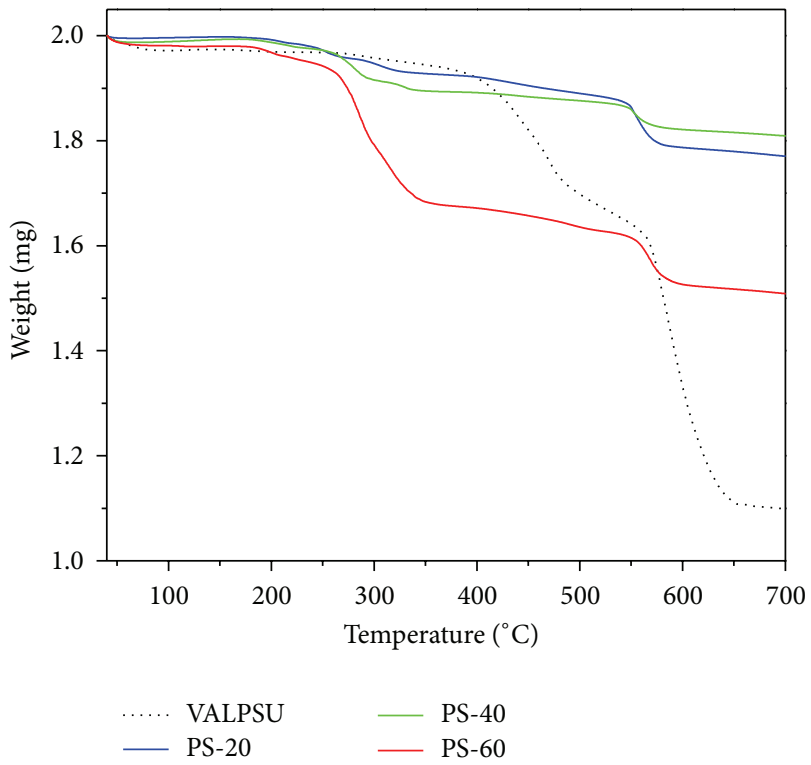

FIGURE 3: TGA thermograms of VALPSU and sulfanilic acid modified VALPSU polymers at a heating rate of $10^{\circ} \mathrm{C} / \mathrm{min}$ under nitrogen atmosphere.

Plots of $-\ln (\ln (-1 / y))$ versus $1 / T$ (Figures 4 (a) and 4(b)) were developed for the decomposition segments of sulfanilic acid modified VALPSU polymers. From the plots, the activation energy $\left(E_{a}\right)$ and frequency factor $(\ln A)$ were evaluated. The enthalpy $(\Delta H)$, entropy $(\Delta S)$, and free energy $(\Delta G)$ have been calculated using standard equations and are summarized in Table 1.

Thermogravimetric analysis was carried out for all the PP20, PP-40, PP-60, PE-20, PA-20, PE-40, and PA-60 polymers; the patterns are presented in Figures 5, 6(a), and 6(b). Polymers bearing pendant units obviously showed moderate thermal stability compared to VALPSU. PA-20 and PA- 40 are predominantly more stable than their respective ester derivatives, PE-20 and PE-40, respectively. But these are adequately less stable to their respective bromoderivatives, that is, PP-20 and PP- 40 polymers.

PE-60 and PA-60 were not attained because the 60 weight $\% 4$-bromoaniline modified polymer (PP-60) was not soluble in DMSO to proceed for further steps.

Figures 7 and 8 illustrate that the plots of $-\ln (\ln (-1 / y))$ versus $1 / T$ were developed for the decomposition segment 


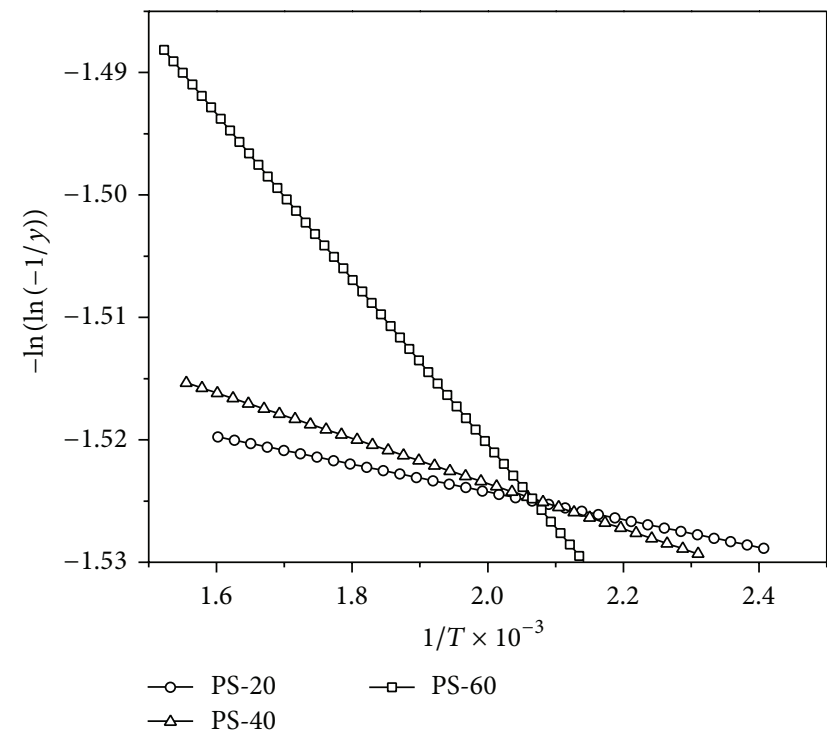

(a)

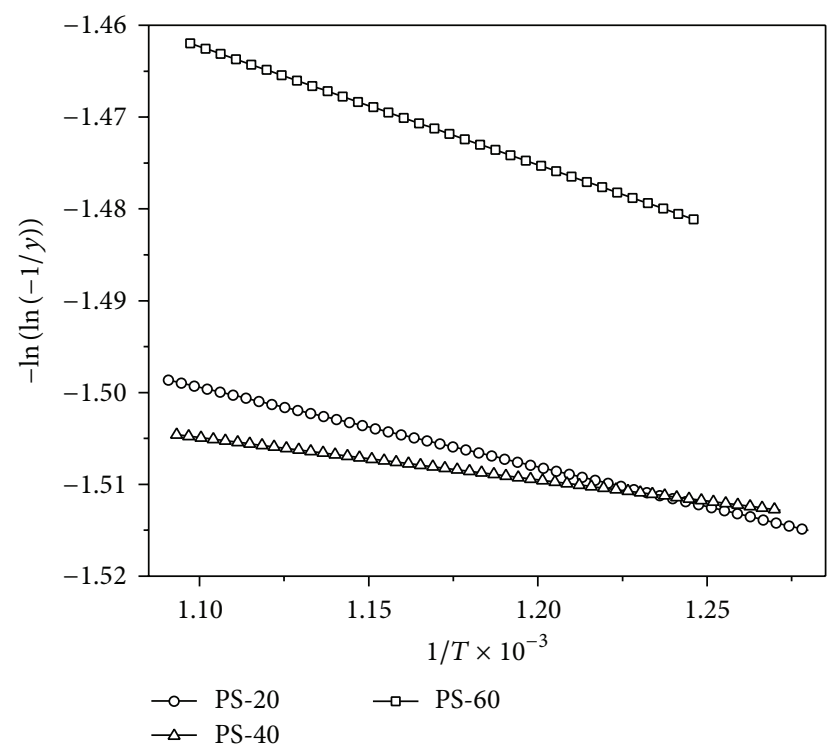

(b)

Figure 4: (a) Plots of $-\ln (\ln (-1 / y))$ versus $1 / T \times 10^{-3}$ for the first decomposition of sulfanilic acid modified VALPSU polymer. (b) Plots of $-\ln (\ln (-1 / y))$ versus $1 / T \times 10^{-3}$ for the second decomposition of sulfanilic acid modified VALPSU polymer.

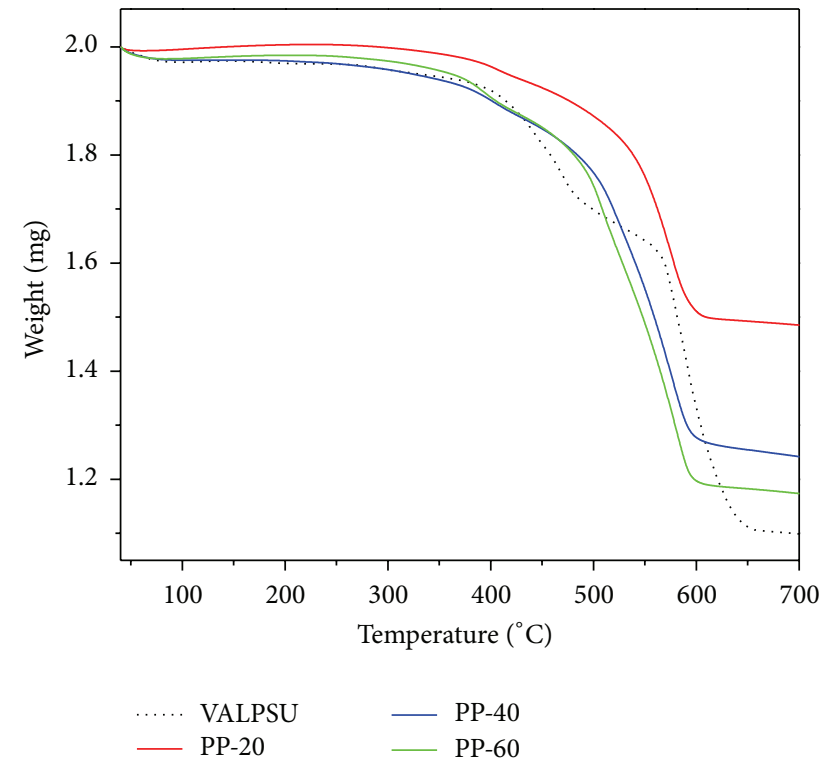

FIGURE 5: TGA thermograms of 4-bromoaniline modified VALPSU polymers at a heating rate of $10^{\circ} \mathrm{C} / \mathrm{min}$ under nitrogen atmosphere.

4-bromoaniline and its respective phosphonated derivatives of VALPSU polymers. From the plots, the activation energy $\left(E_{a}\right)$ and frequency factor $(\ln A)$ were evaluated. The enthalpy $(\Delta H)$, entropy $(\Delta S)$, and free energy $(\Delta G)$ have been calculated using standard equations and are summarized in Table 2. The result indicates that the activation energies for PE-20 and PE-40 compared to PA-20 and PA-40 are lower, signposting that the decomposition step is faster. Decomposition of PP-20 was faster in comparison to PP60 , as PP-20 including the much carboxylic acid moieties in addition to the 4-bromophenyl pendants suffers faster decomposition than PP-60.

3.3. Frequency Dependence ac Conductivity $\left(\sigma_{a c}\right)$, Dielectric Constant $\left(\varepsilon^{\prime}\right)$, and Dielectric Loss $(\tan \delta)$. From Figure 9, it is observed that the variation of conductivity as a function of frequency at ambient temperature does not vary much with frequency and is almost negligible; since VALPSU is an insulating material, at lower frequencies the ac conductivity depends on the nature of dielectric nature of the material. Above $5 \mathrm{MHz}, \sigma_{\mathrm{ac}}$ varies and increases steeply and linearly follows classical hopping model [33].

The plot of variation of dielectric constant as a function of $\log$ (f requency) at room temperature is shown in Figure 10. The plot illustrates that it is generally followed by almost all the dielectric and ferroelectric materials. The dielectric constant drops at high frequencies; this is due to the fact that the dipoles can no longer follow the high frequencies; the dielectric constant of 177 is achieved for the 60 weight $\%$ of sulfanilic acid to VALPSU. Minimum dielectric constant $\left(\varepsilon^{\prime}\right)$ value of 155 was obtained for PA-40. The higher ionic moieties in the VALPSU upshot the lower dielectric constant $[34,35]$ and it may also be due to affecting factor of increasing amide functional groups in the polymeric chain.

Frequency dependence variations of dielectric loss at room temperature were presented in Supplementary Material (Figure S5). As per the plot $\tan \delta$ decreases with increase of frequency and attains the constant value. The dielectric loss of all the sulfanilic acid modified polymers is lower than 0.18; at $2 \mathrm{MHz} \tan \delta$ was well below 0.07 but the respective phosphonic derivatives display 0.02 with increasing frequency which is due to low ion drifting and restriction in dipole polarisation due to polar groups in the polymeric chain. 


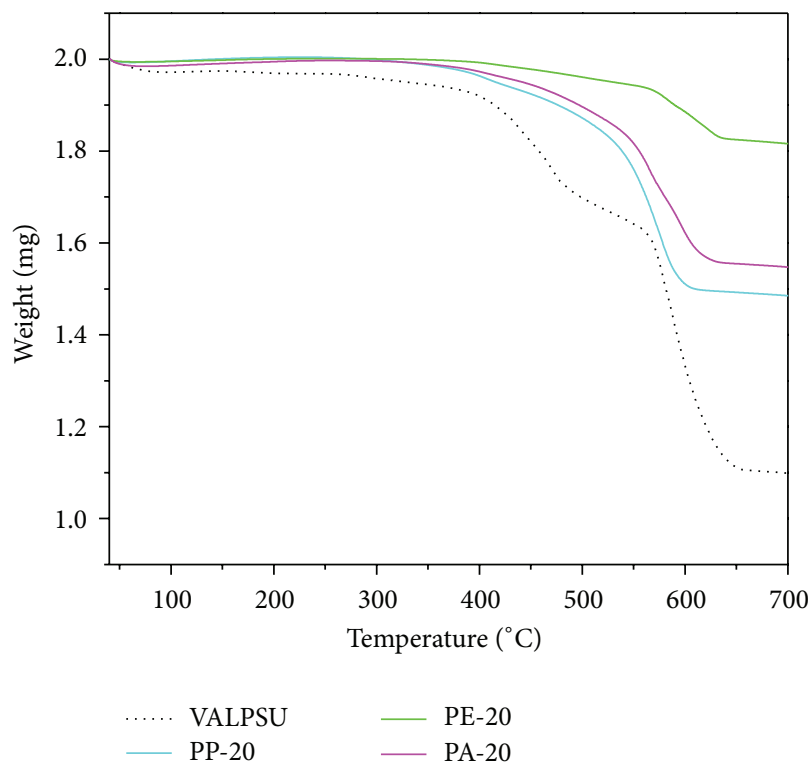

(a)

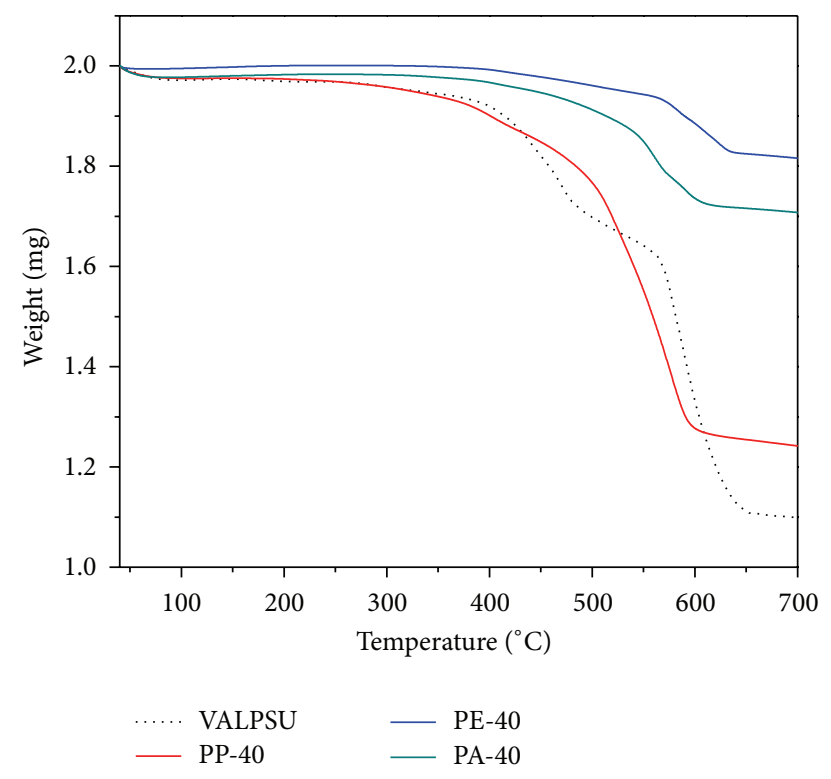

(b)

Figure 6: (a) TGA thermograms of phosphonated derivatives of VALPSU polymers (20 weight \%) at a heating rate of $10^{\circ} \mathrm{C} / \mathrm{min}$ under nitrogen atmosphere. (b) TGA thermograms of phosphonated derivatives of VALPSU polymers (40 weight $\%$ ) at a heating rate of $10^{\circ} \mathrm{C} / \mathrm{min}$ under nitrogen atmosphere.

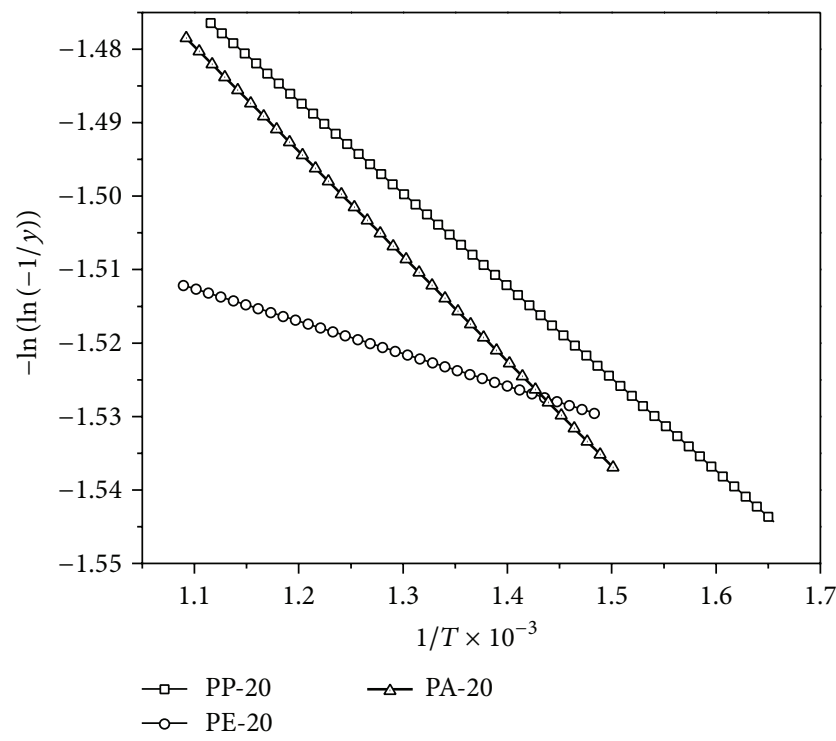

(a)

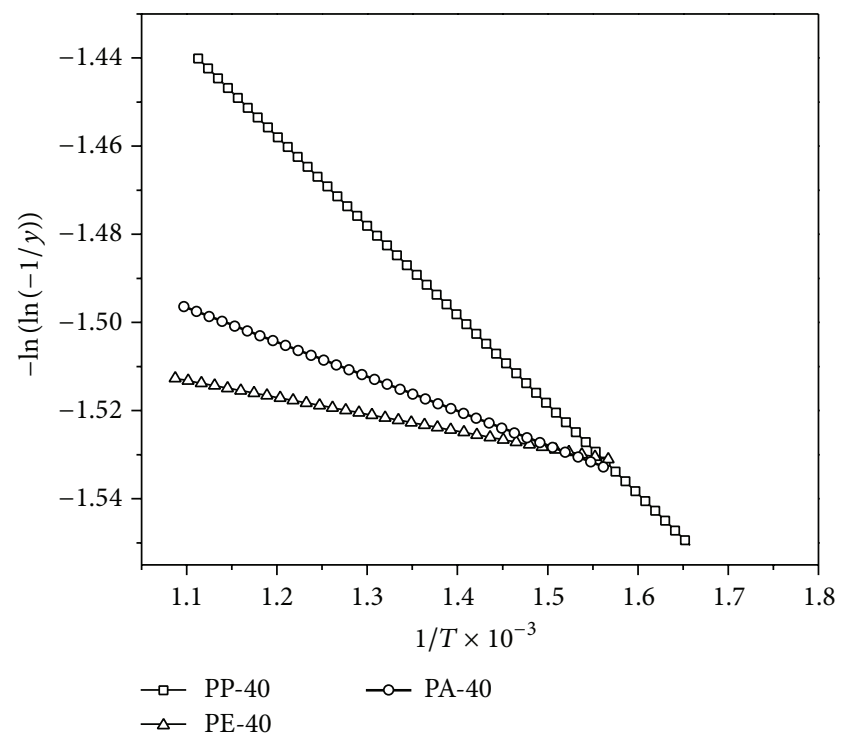

(b)

Figure 7: (a) Plots of $-\ln (\ln (-1 / y))$ versus $1 / T \times 10^{-3}$ for the phosphonated derivatives of modified VALPSU polymer (20 weight \%). (b) Plots of $-\ln (\ln (-1 / y))$ versus $1 / T \times 10^{-3}$ for the phosphonated derivatives of modified VALPSU polymer $(40$ weight $\%)$.

\section{Conclusion}

Dielectric ionomers with pendant phenyl sulfonic acid and phenyl phosphonic acid moieties were synthesized and well characterized. The analytical and spectral data were well consistent with the proposed structures of modified VALPSU. All the modified polymers exhibit good thermal stability which was confirmed by TGA. The VALPSU having phenyl phosphonic acid units shows better thermal stability than the phenyl sulfonic acid moieties. Adopting Broido method to the decomposition steps of phosphonic ester and phosphonic acid derivatives clearly indicates that VALPSU having phosphonic acid units undergoes decomposition much slower compared to the phosphonic ester derivatives. As the content 


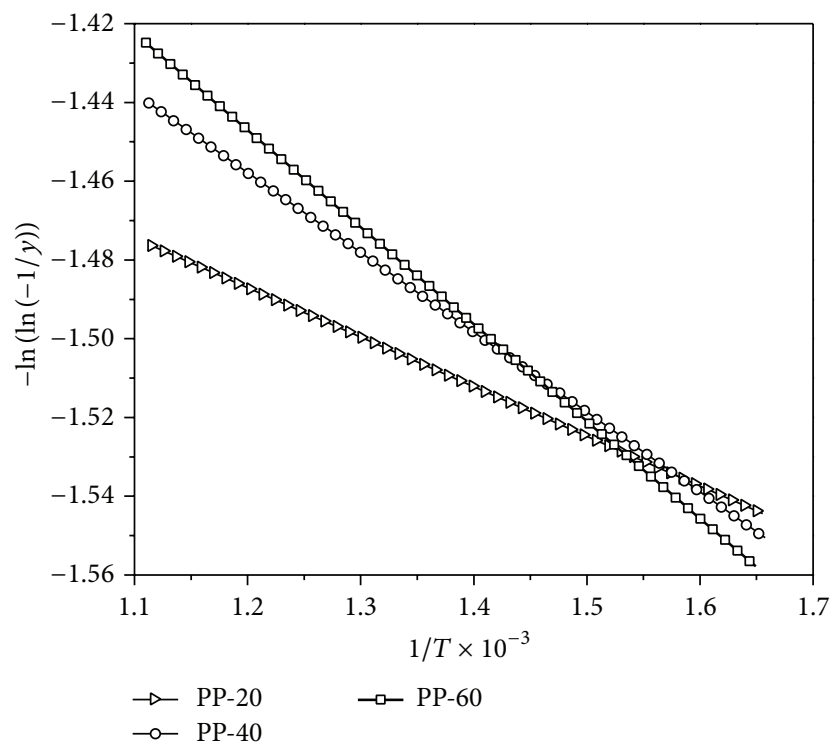

FIGURE 8: Plots of $-\ln (\ln (-1 / y))$ versus $1 / T \times 10^{-3}$ for the 4 -bromoaniline modified VALPSU polymer.

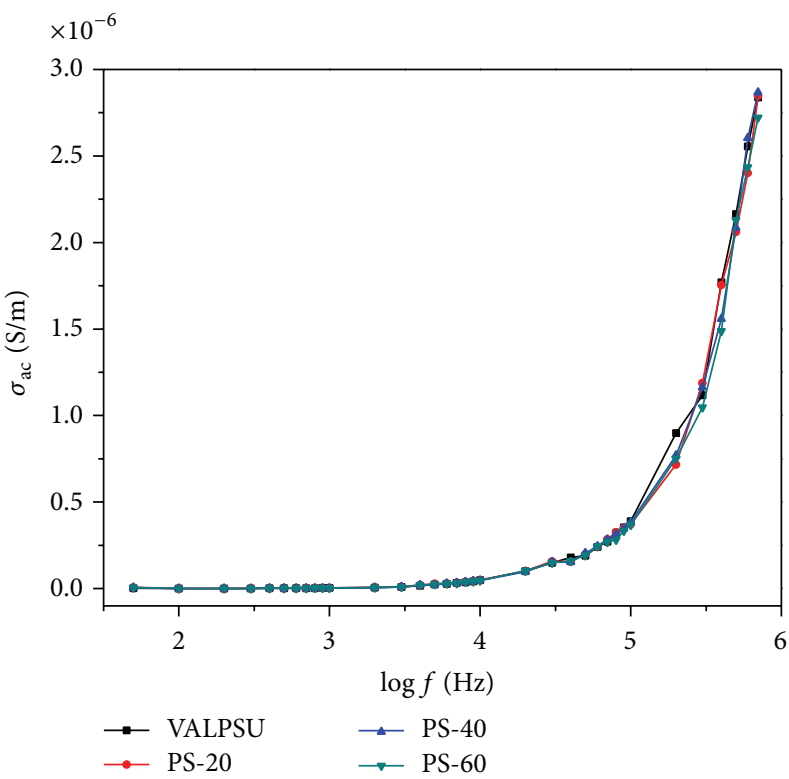

(a)

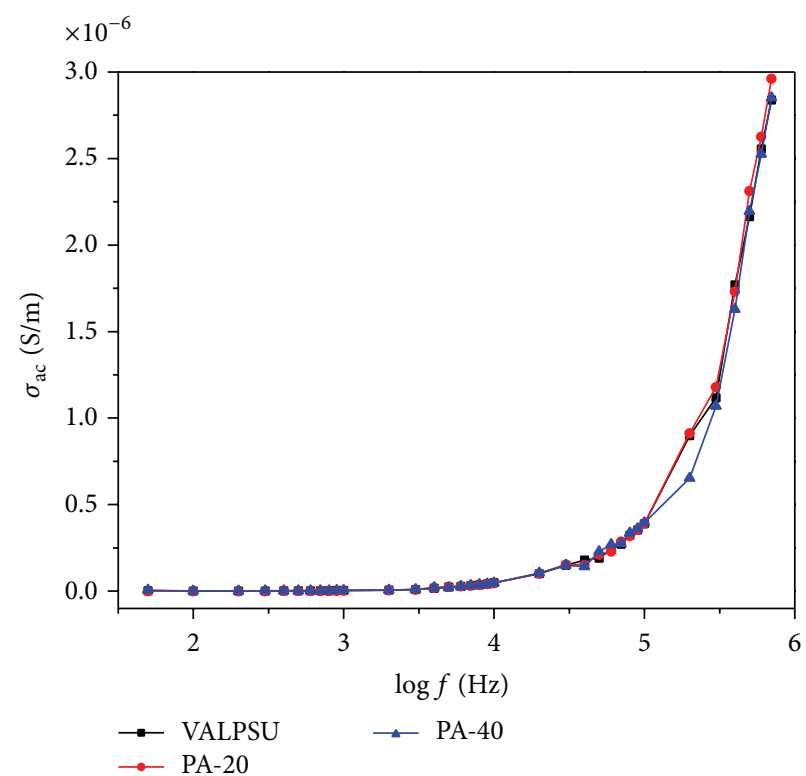

(b)

FIGURE 9: Room temperature variation of ac conductivity with $\log$ (frequency) for VALPSU and modified VALPSU.

TABLE 2: Kinetic and thermodynamic parameters of modified phosphonated VALPSU.

\begin{tabular}{lcccccc}
\hline Samples & Decomposition range $\left({ }^{\circ} \mathrm{C}\right)$ & $E_{a}(\mathrm{~kJ} / \mathrm{mol}) \times 10^{-3}$ & $\ln A$ & $\Delta H(\mathrm{~kJ} / \mathrm{mol})$ & $\Delta S(\mathrm{~kJ} / \mathrm{K})$ & $\Delta G(\mathrm{~kJ} / \mathrm{mol})$ \\
\hline PP-20 & $330-625$ & 2.41 & -9.444 & -6.241 & -161.89 \\
PP-40 & $330-625$ & 3.88 & -8.824 & -6.239 & -161.64 & 121.57 \\
PP-60 & $335-630$ & 4.72 & -8.549 & -6.261 & -161.59 \\
PE-20 & $400-645$ & 0.84 & -10.633 & -6.620 & -161.72 & 121.78 \\
PA-20 & $395-645$ & 2.73 & -9.272 & -6.577 & -161.53 & 128.78 \\
PE-40 & $365-645$ & 0.73 & -10.789 & -6.477 & -161.85 \\
PA-40 & $365-640$ & 1.49 & -9.999 & -6.453 & -161.74 & 127.85 \\
\hline
\end{tabular}




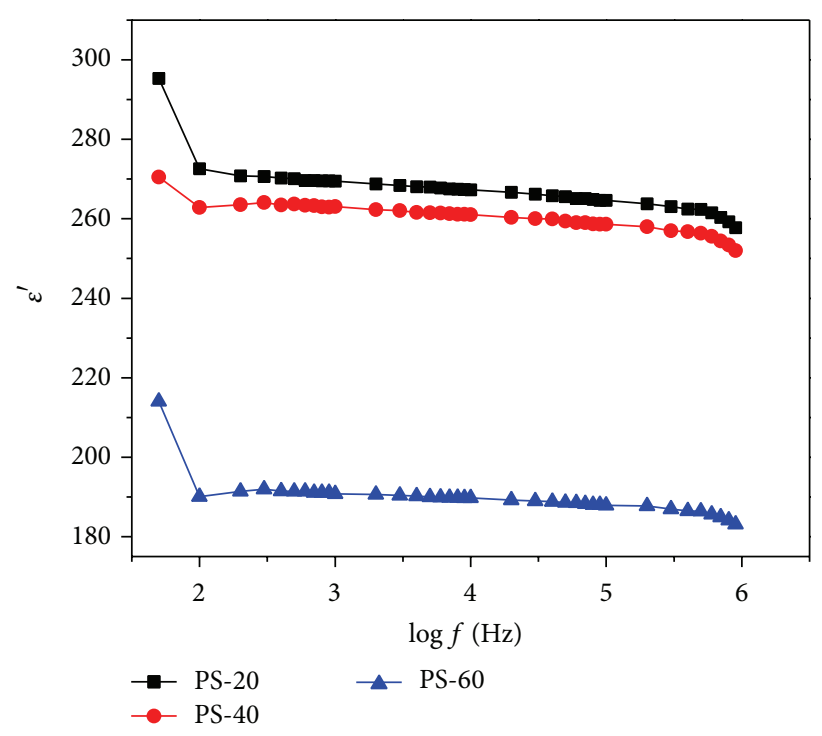

(a)

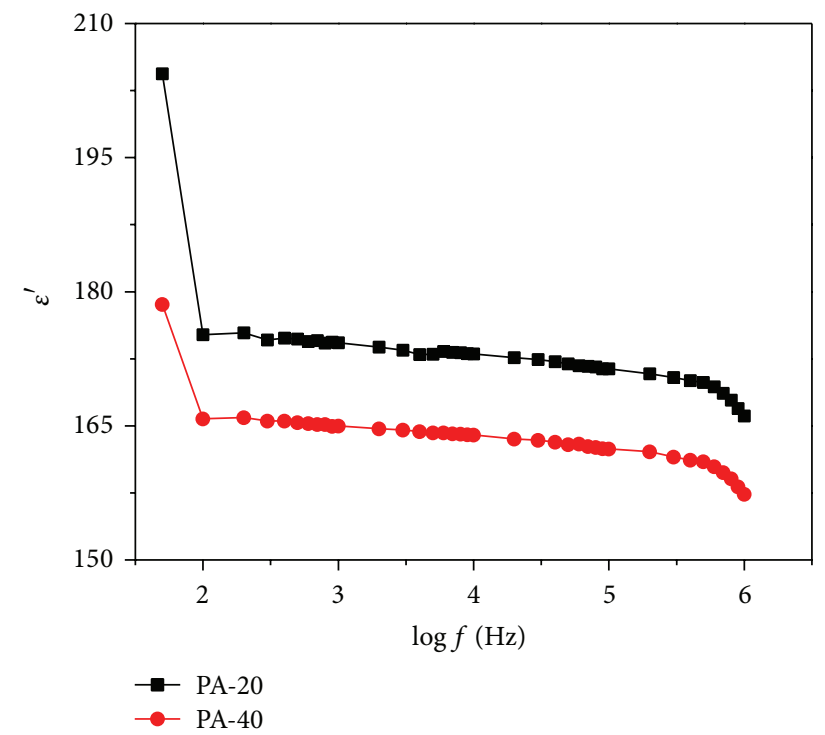

(b)

FIGURE 10: Room temperature variation of dielectric constant $\left(\varepsilon^{\prime}\right)$ with $\log$ (frequency) of modified VALPSU polymer.

of phenyl sulfonic acid and phenyl phosphonic acid units increased in the VALPSU, we observed the decrease in the dielectric constant and it reaches 155 from 488 for the 40 weight $\%$ of phosphonic acid derivative of VALPSU. All the modified polymers suffer low dielectric loss below 0.3 . These low dielectric constant and low loss materials with adequate thermal stability are prime candidates in microelectronics and can replace selectively the ceramic and glass materials to make them applicable in high operating frequencies devices.

\section{Competing Interests}

It is to be stated that neither authors nor their institution has a financial or other relationship with any organization or people that may influence the authors' work. Authors are not being paid by any organization or agency related to the product. The authors declare that they have no competing interests.

\section{Acknowledgments}

The authors gratefully acknowledge IISc, STIC, and SICART for providing NMR, TGA, and GPC measurements.

\section{References}

[1] I. H. Hristov, S. J. Paddison, and R. Paul, "Molecular modeling of proton transport in the short-side-chain perfluorosulfonic acid ionomer," Journal of Physical Chemistry B, vol. 112, no. 10, pp. 2937-2949, 2008.

[2] R. Tayouo, G. David, and B. Améduri, "New fluorinated polymers bearing pendant phosphonic groups for fuel cell membranes-part 1 synthesis and characterizations of the fluorinated polymeric backbone," European Polymer Journal, vol. 46, no. 5, pp. 1111-1118, 2010.

[3] O. Pinprayoon, R. Groves, P. A. Lovell, S. Tungchaiwattana, and B. R. Saunders, "Polymer films prepared using ionically crosslinked soft core-shell nanoparticles: a new class of nanostructured ionomers," Soft Matter, vol. 7, no. 1, pp. 247-257, 2011.

[4] E. P. Jutemar, S. Takamuku, and P. Jannasch, "Sulfonated poly(arylene ether sulfone) ionomers containing di- and tetrasulfonated arylene sulfone segments," Polymer Chemistry, vol. 2, no. 1, pp. 181-191, 2011.

[5] R. Shankar, T. K. Ghosh, and R. J. Spontak, "Dielectric elastomers as next-generation polymeric actuators," Soft Matter, vol. 3, no. 9, pp. 1116-1129, 2007.

[6] J. W. Nicholson, "Polyelectrolyte materials-reflections on a highly charged topic," Chemical Society Reviews, vol. 23, no. 1, pp. 53-58, 1994.

[7] C. A. G. N. Montalbetti and V. Falque, "Amide bond formation and peptide coupling," Tetrahedron, vol. 61, no. 46, pp. 1082710852, 2005.

[8] H.-L. Wu, C.-C. M. Ma, C.-H. Li et al., "Sulfonated poly(ether ether ketone)/poly(amide imide) polymer blends for proton conducting membrane," Journal of Membrane Science, vol. 280, no. 1-2, pp. 501-508, 2006.

[9] F. Kremer, L. Dominguez, W. H. Meyer, and G. Wegner, "Thermal and dielectric properties of glassy ionenes," Polymer, vol. 30, no. 11, pp. 2023-2029, 1989.

[10] H. Jiang, L. Hong, N. Venkatasubramanian et al., "The relationship between chemical structure and dielectric properties of plasma-enhanced chemical vapor deposited polymer thin films," Thin Solid Films, vol. 515, no. 7-8, pp. 3513-3520, 2007.

[11] R. J. Cava, "Dielectric materials for applications in microwave communications," Journal of Materials Chemistry, vol. 11, no. 1, pp. 54-62, 2011. 
[12] B. Liu, G. P. Robertson, D.-S. Kim, M. D. Guiver, W. Hu, and Z. Jiang, "Aromatic poly(ether ketone)s with pendant sulfonic acid phenyl groups prepared by a mild sulfonation method for proton exchange membranes," Macromolecules, vol. 40, no. 6, pp. 1934-1944, 2007.

[13] F. Wang, M. Hickner, Q. Ji et al., "Synthesis of highly sulfonated poly(arylene ether sulfone) random (statistical) copolymers via direct polymerization," Macromolecular Symposia, vol. 175, pp. 387-395, 2001.

[14] D. S. Kim, G. P. Robertson, and M. D. Guiver, "Comb-shaped poly(arylene ether sulfone)s as proton exchange membranes," Macromolecules, vol. 41, no. 6, pp. 2126-2134, 2008.

[15] Y. Z. Meng, S. C. Tjong, A. S. Hay, and S. J. Wang, "Synthesis and proton conductivities of phosphonic acid containing poly(arylene ether)s," Journal of Polymer Science, Part A: Polymer Chemistry, vol. 39, no. 19, pp. 3218-3226, 2001.

[16] F. Liu, J. Ding, M. Li, M. Day, G. Robertson, and M. Zhou, "Preparation of highly fluorinated poly(ether sulfone)s under mild polycondensation conditions using molecular sieves," Macromolecular Rapid Communications, vol.23, no. 14, pp. 844848, 2002.

[17] C. Sanchez, P. Belleville, M. Popall, and L. Nicole, "Applications of advanced hybrid organic-inorganic nanomaterials: from laboratory to market," Chemical Society Reviews, vol. 40, no. 2, pp. 696-753, 2011.

[18] K. Yang, H. Liang, and J. Lu, "Multifunctional star polymer with reactive and thermosensitive arms and fluorescently labeled core: synthesis and its protein conjugate," Journal of Materials Chemistry, vol. 21, no. 28, pp. 10390-10398, 2011.

[19] L. Brunsveld, B. J. B. Folmer, E. W. Meijer, and R. P. Sijbesma, "Supramolecular polymers," Chemical Reviews, vol. 101, no. 12, pp. 4071-4097, 2001.

[20] J. Hopkins and J. P. S. Badyal, "Plasma modification of poly(ether sulfone)," Macromolecules, vol. 27, no. 19, pp. 54985503, 1994.

[21] I. Pinnau, J. Wind, and K. V. Peinemann, "Ultrathin multicomponent poly(ether sulfone) membranes for gas separation made by dry/wet phase inversion," Industrial \& Engineering Chemistry Research, vol. 29, no. 10, pp. 2028-2032, 1990.

[22] L. Zhao, D. Jianfu, G. P. Robertson, and M. D. Guiver, "A novel bisphenol monomer with grafting capability and the resulting poly(arylene ether sulfone)s," Macromolecules, vol. 39, no. 20, pp. 6990-6996, 2006.

[23] T. Suga, S. Wi, and T. E. Long, "Synthesis of Diazocinecontaining poly(arylene ether sulfone)s for tailored mechanical and electrochemical performance," Macromolecules, vol. 42, no. 5, pp. 1526-1532, 2009.

[24] C. Wang, N. Li, D. W. Shin et al., "Fluorene-based poly(arylene ether sulfone)s containing clustered flexible pendant sulfonic acids as proton exchange membranes," Macromolecules, vol. 44, no. 18, pp. 7296-7306, 2011.

[25] Y. Takebe, K. Hochi, and Y. Shirota, "Ionic conductivities of hybrid films composed of comb polymers containing esters as pendant groups and lithium trifluoromethane sulfonate," Solid State Ionics, vol. 60, no. 1-3, pp. 125-130, 1993.

[26] S. Zhou, J. Kim, and D. Kim, "Cross-linked poly(ether ether ketone) membranes with pendant sulfonic acid groups for fuel cell applications," Journal of Membrane Science, vol. 348, no. 1-2, pp. 319-325, 2010.

[27] A. P. Demchenko, K. C. Tang, and P. T. Chou, "Excitedstate proton coupled charge transfer modulated by molecular structure and media polarization," Chemical Society Reviews, vol. 42, no. 3, pp. 1379-1408, 2013.

[28] I. Capek, "Nature and properties of ionomer assemblies. II," Advances in Colloid and Interface Science, vol. 118, no. 1-3, pp. 73-112, 2005.

[29] N. V. Kawahara and H. Ohno, "Stability of poly(ethylene oxide)-modified myoglobin in ion conductive polymers at high temperatures," Solid State Ionics, vol. 113-115, pp. 161-166, 1998.

[30] S. D. Ganesh, M. N. Harish, B. J. Madhu, H. Maqbool, K. V. Pai, and M. Y. Kariduraganavar, "Poly(arylene ether sulfone)s with HEPES pendants: synthesis, thermal, and dielectric studies," ISRN Polymer Science, vol. 2013, Article ID 897034, 7 pages, 2013.

[31] J. W. Paquette, K. J. Kim, and D. Kim, "Low temperature characteristics of ionic polymer-metal composite actuators," Sensors and Actuators A: Physical, vol. 118, no. 1, pp. 135-143, 2005.

[32] A. Broido, "A simple, sensitive graphical method of treating thermogravimetric analysis data," Journal of Polymer Science Part A-2: Polymer Physics, vol. 7, no. 10, pp. 1761-1773, 1969.

[33] P. Kumar, K. S. Bindra, N. Suri, and R. Thangaraj, “Transport properties of a- $\mathrm{Sn}_{x} \mathrm{Sb}_{20} \mathrm{Se}_{80-x}(18 \leq x \leq 18)$ chalcogenide glass," Journal of Physics D: Applied Physics, vol. 39, no. 4, pp. 642-646, 2006.

[34] D. L. Sidebottom, B. Rolling, and K. Funke, "Ionic conduction in solids: comparing conductivity and modulus representations with regard to scaling properties," Physical Review B: Condensed Matter, vol. 63, Article ID 024301, 2000.

[35] L. G. Allegen and B. Norberg, "A dielectric study of two acid polyelectrolytes, phosvitin and a polymetaphosphate," Biochimica et Biophysica Acta, vol. 32, pp. 514-518, 1959. 

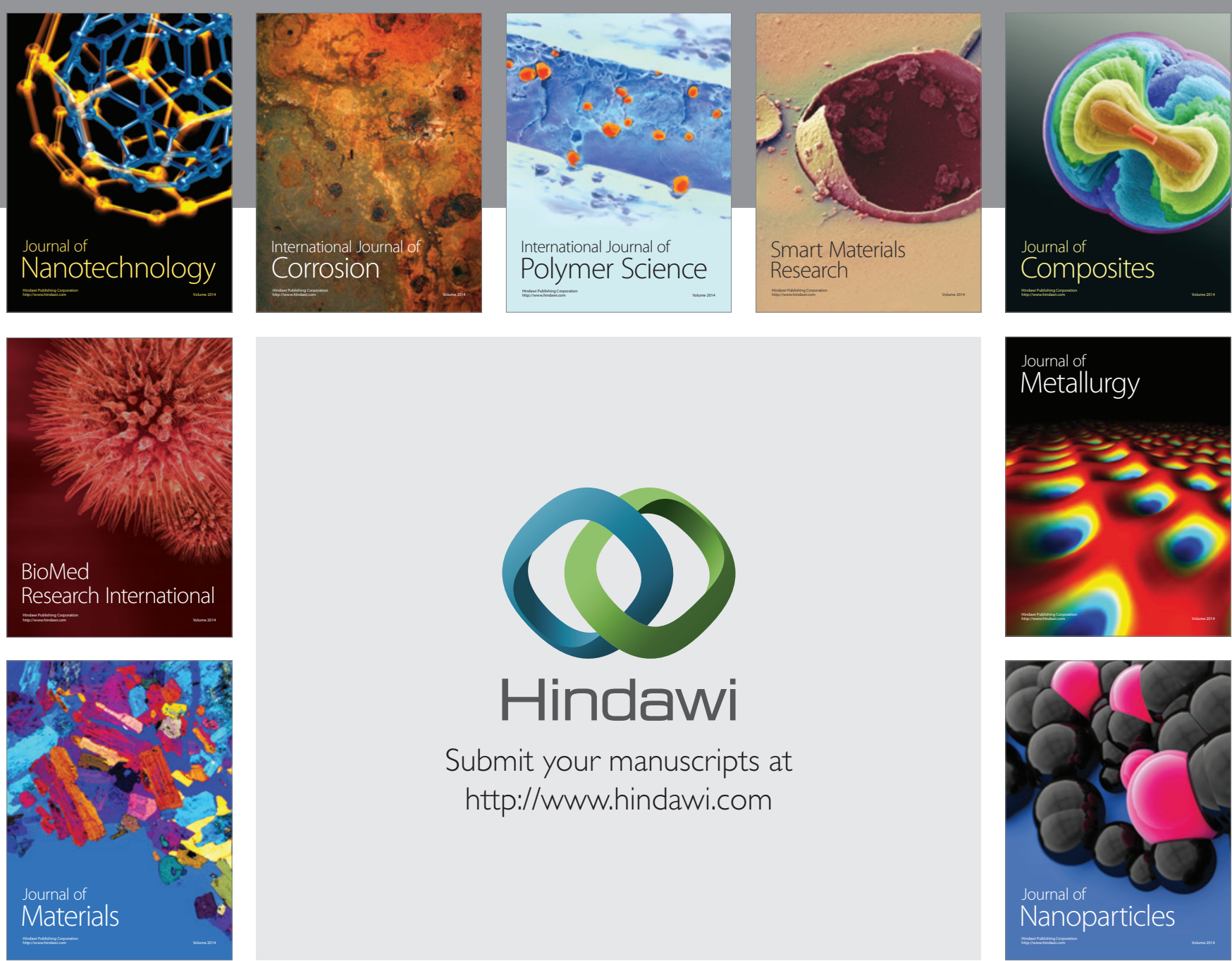

\section{Hindawi}

Submit your manuscripts at

http://www.hindawi.com

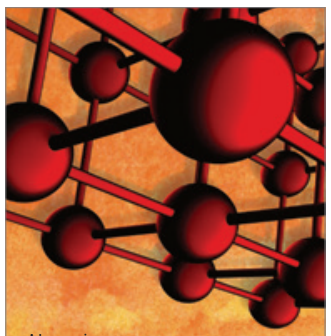

Materials Science and Engineering
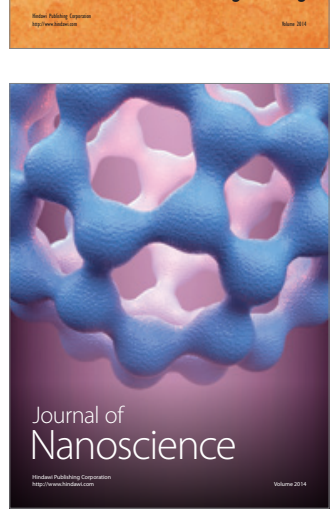
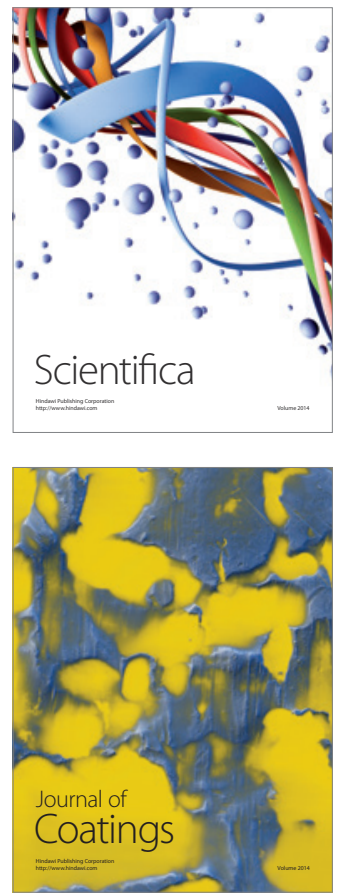
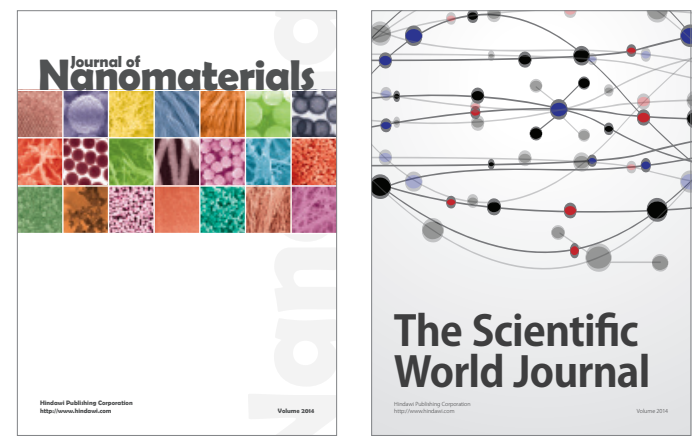

The Scientific World Journal
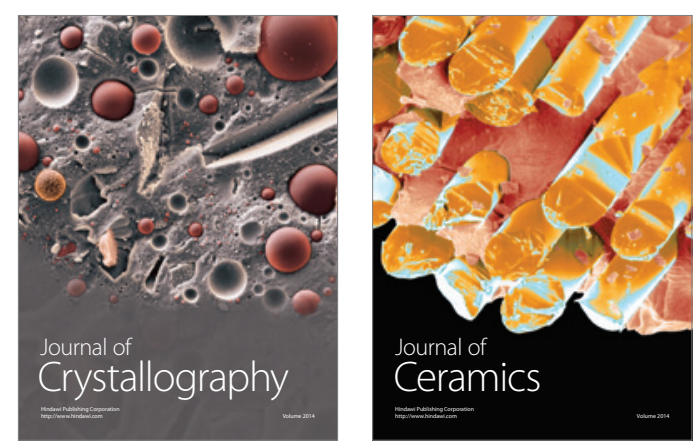
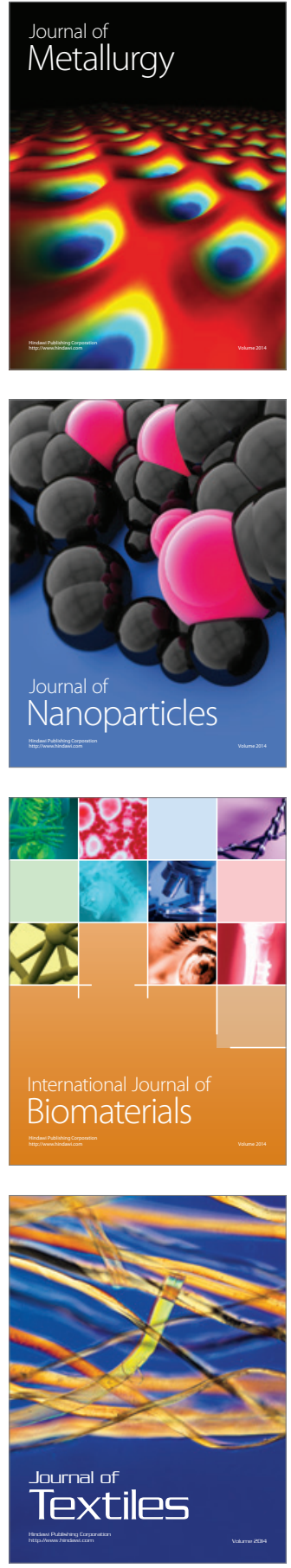